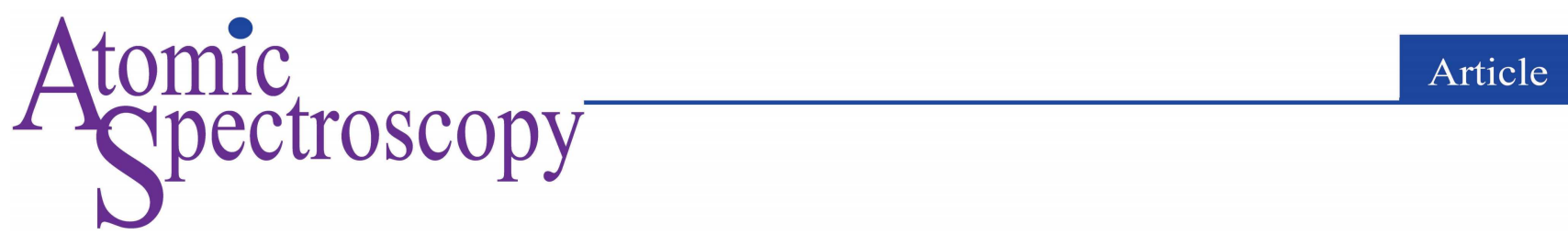

\title{
Direct Seawater Analysis by High-Resolution ICP-MS Provides Insights into Toxic Metal Accumulation in Marine Sediments
}

\author{
Olga V. Kuznetsova* and Andrei R. Timerbaev \\ Vernadsky Institute of Geochemistry and Analytical Chemistry, Russian Academy of Sciences, Kosygin Str. 19, 119991 Moscow, Russian Federation
}

Received: November 16, 2020; Revised: December 06, 2020; Accepted: December 06, 2020; Available online: December 10, 2020.

DOI: $10.46770 / A S .2021 .005$

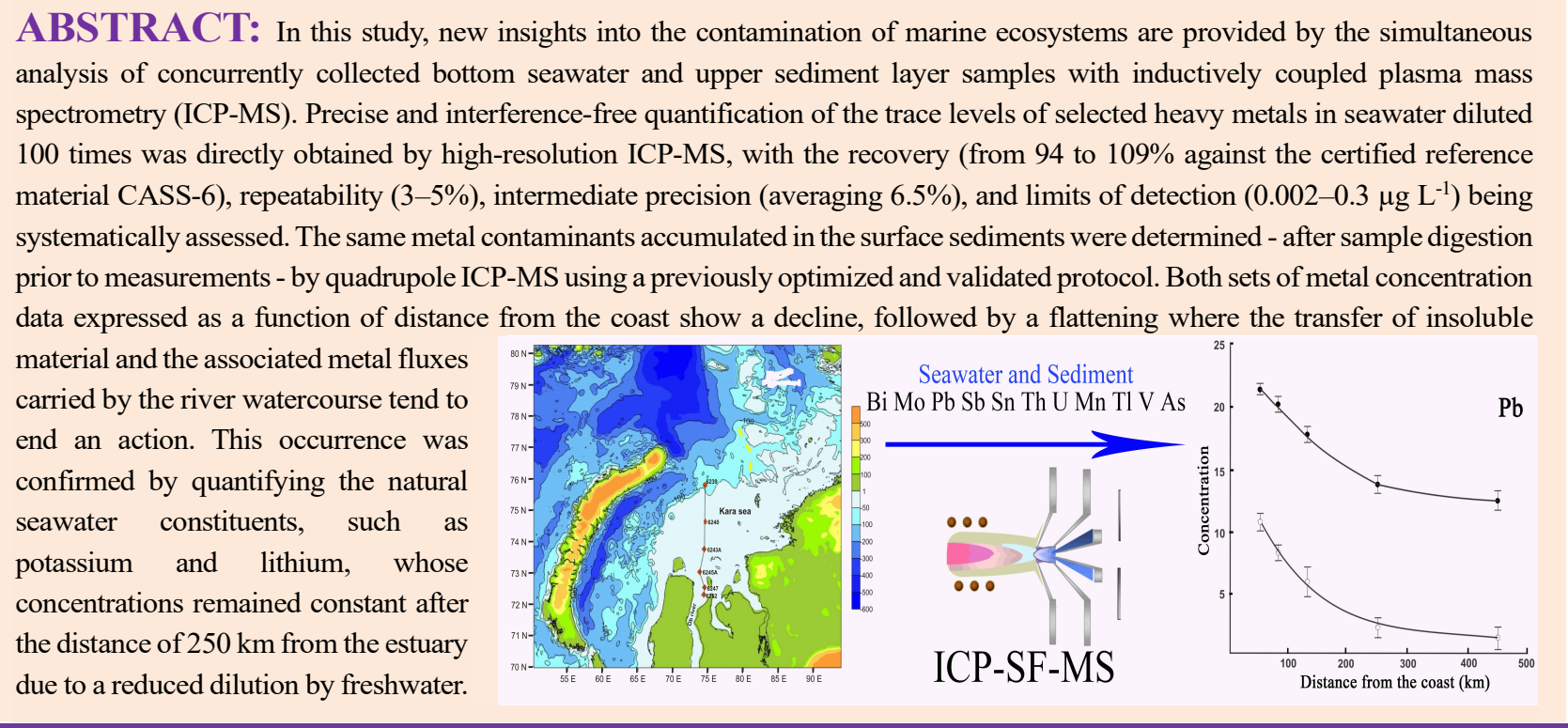

\section{INTRODUCTION}

When analytical approaches for the accurate quantification of trace metals in seawater are considered, inductively coupled plasma mass spectrometry (ICP-MS) advances to the forefront. The examination of recent publications reveals that the ICP-MS technique, operating in high-resolution mode, received highest response from the field. Particularly, there are frequent successful attempts of using sector-field (SF) ICP-MS to determine a variety of metals occurring in seawater at low and even sub-ng $\mathrm{L}^{-1}$ levels (see refs. 1-5 to mention a few). However, sample preparation is typically mandatory and involves analyte pre-concentration and matrix separation to transfer the enriched metals into a solution, thus ensuring ICP-MS measurements free from interferences from the salt matrix. Evidently, such treatment, commonly based on using the chelating resins variable in complexation chemistry, ${ }^{6-8}$ makes the analytical protocol more complicated and prone to uncertainties. Examples of the simultaneous determination of trace metals in seawater by SF-ICP-MS without intricate sample treatment are very few ${ }^{9,10}$ and other direct applications are singleelement approaches. ${ }^{11,12}$

As a matter of fact, dilution may serve as an alternative to cope with the high salinity matrix, at least when determining more abundant metals, ${ }^{9,10,12}$ given the extremely high sensitivity of SFICP-MS. This approach has been explored in our study aimed at validating an analytical procedure for the simultaneous measurement of various metals in seawater, which can be suitable for large-scale monitoring of metal contaminants (where high sample throughput is a prerequisite). The satisfactory analytical performance of the method was proved through the analysis of certified reference material (CRM), CASS-6, and systematic metal determinations in bottom seawater, collected from 50 to 450 
$\mathrm{km}$ from the continental shelf, with the limits of quantification at the low- to sub- $\mu \mathrm{g} \mathrm{L}^{-1}$ levels.

Our particular interest in such an analysis is because in the case of shallow seas, such as the Kara Sea (part of the Arctic Ocean) and part in our investigation, the water column may be contaminated by toxic metals carried by river current, the effect of which remains in force over a long distance from the estuary. Another important source of contamination may be the inflow of aerosol material, including particles of mineral dust, volcanic ash, organic combustion products from forest fires, industry and transport products. ${ }^{13,14}$ However, in the case of the Kara Sea, river runoffs are thought to make the main contribution. In the event of an assumed geochemical scenario, metal accumulation in the sediments would present one of the largest threats to the environment. Therefore, we consider the harmonized surveying of surface sediments and overlaying seawater in terms of the level of selected heavy metals, performed here by the verified ICP-MS method, as a valid strategy to assess the ecological state of this marine environment.

\section{EXPERIMENTAL}

Reagents and materials. Stock solutions $\left(10 \mathrm{mg} \mathrm{L}^{-1}\right)$ used to prepare the mixed standard solutions and the internal standard (High-Purity Standards, Charleston, SC, USA) were diluted appropriately with $3 \% \mathrm{HNO}_{3}$, prepared from ultrapure nitric acid (65\%, Merck, Germany) and ultrapure water. Seawater CRM (CASS-6, A33-11-02-CASS) was purchased from the National Research Council of Canada (Ottawa, ON, Canada). All plastic, quartz and glassware were soaked in $4 \mathrm{~mol} \mathrm{~L}^{-1} \mathrm{HNO}_{3}$ for at least $24 \mathrm{~h}$ and rinsed repeatedly with ultrapure water before use.

Instrumentation. The seawater analyses were performed on an Element-2 SF-ICP-MS instrument (Thermo Fisher Scientific, Waltham, MA, USA) with high resolution capacity. The instrument was used in three nominal resolution settings: low ( $\mathrm{R}$ $=300)$, medium $(\mathrm{R}=4000)$ and high $(\mathrm{R}=10000)$. The metal isotopes were analyzed in appropriate resolutions (see Table 1 for more detail) to eliminate polyatomic interferences. The internal standard ${ }^{115} \mathrm{In}\left(1 \mu \mathrm{g} \mathrm{L}^{-1}\right)$ was analyzed in both resolutions to account for any drift variation within and between the resolution settings over time. Prior to measurements, the instrumental conditions (including torch position, sample gas flow rate, and lens settings) were optimized to achieve high, reproducible signal intensities and a low oxide level $\left(\mathrm{UO}^{+}\right)$in a $1 \mu \mathrm{g} \mathrm{L}^{-1}$ tune solution $(<4 \%)$. The ICP-MS operating parameters are listed in Table 1. In the case of sediment analyses, the instrumental and measurements conditions were as previously described. ${ }^{15}$

Sampling. Both the seawater and sediment samples were collected in August-September 2019 on the continental shelf of the Kara Sea during a research oceanographic cruise aboard the R.V.

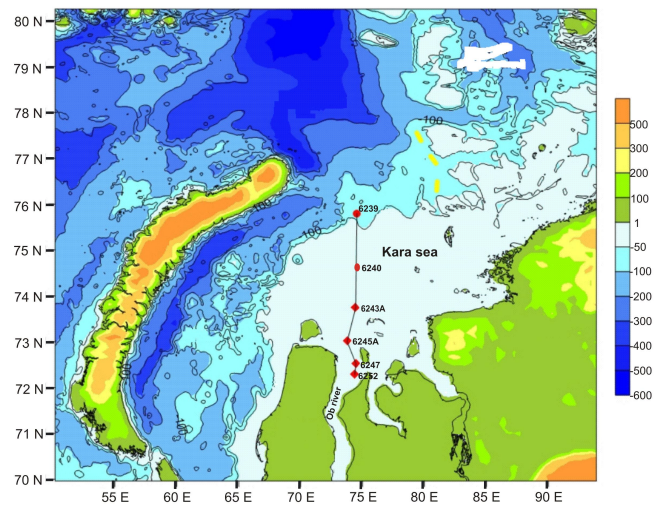

Fig. 1 Sampling area.

Table 1. SF-ICP-MS Measurement Parameters

\begin{tabular}{ll}
\hline Parameter & Setting \\
\hline Plasma gas flow, L/min & 14 \\
Auxiliary gas flow, L/min & 0.9 \\
Nebulizer Ar flow, L/min & 0.9 \\
Sample gas flow, mL/min & 0.8 \\
RF power, W & 1250 \\
Dwell time, ms & 10,20 or 50 for low, middle or high \\
Spectral resolution mode & low $\left({ }^{209} \mathrm{Bi},{ }^{111} \mathrm{Cd},{ }^{7} \mathrm{Li},{ }^{95} \mathrm{Mo},{ }^{208} \mathrm{~Pb},{ }^{85} \mathrm{Rb}\right.$, \\
& $\left.{ }^{121} \mathrm{Sb},{ }^{118} \mathrm{Sn},{ }^{88} \mathrm{Sr},{ }^{232} \mathrm{Th},{ }^{205} \mathrm{Tl},{ }^{238} \mathrm{U}\right) ;$ \\
& medium $\left({ }^{55} \mathrm{Mn},{ }^{51} \mathrm{~V}\right) ;$ \\
\hline
\end{tabular}

Academician Mstislav Keldysh. The sediment material was the upper layer (maximum $10 \mathrm{~cm}$ in depth), while the seawater was the part of the water column in direct contact with the surface layer collected in duplicate (each sample $1 \mathrm{~L}$ ) into Teflon-lined leveraction Niskin bottles (General Oceanics, Miami, FL, USA) at the same sampling site. The geographical location of the sampling sites is detailed in Fig. 1.

\section{Sample preparation}

Seawater. All seawater samples were filtered through acid precleaned cellulose nitrate membrane filters (Whatman, $0.45 \mu \mathrm{m}$ ) under vacuum and acidified (with $\mathrm{HNO}_{3}$ to $3 \%$ ) on board, stored at $4^{\circ} \mathrm{C}$ and later analyzed at the laboratory facilities, following dilution with $3 \% \mathrm{HNO}_{3}$.

Sediment. Upon collection, the samples were air-dried and homogenized using an agate mortar, oven dried at $50^{\circ} \mathrm{C}$ for 6 days prior to digestion (for more details, see ref. 16) and then transferred to the laboratory for digestion using the previously optimized and validated procedure. ${ }^{15,17,18}$

\section{RESULTS AND DISCUSSION}

Sample dilution factors. When SF-ICP-MS is applied for seawater analysis, dilution is required not only to avoid substantial salt built-up in the sample introduction system but also to reduce 
Table 2. SF-ICP-MS Detection Limits for Seawater Analysis ( $\left.\mu \mathrm{g} \mathrm{L}^{-1}\right)$

\begin{tabular}{|c|c|c|c|c|c|c|c|}
\hline Metal & NASS-5 ${ }^{10}$ & NASS-5 $^{12}$ & NASS- $^{21}$ & NASS- $^{22}$ & CASS-3 $^{19}$ & $\mathrm{CASS} \mathbf{4}^{20}$ & CASS-6 (this study) \\
\hline As & - & - & 0.001 & 0.05 & - & - & 0.24 \\
\hline $\mathbf{B i}$ & - & - & - & - & - & - & 0.13 \\
\hline Cd & - & - & - & - & 0.013 & - & 0.007 \\
\hline Mn & 0.005 & - & - & - & 0.27 & 0.12 & 0.13 \\
\hline Mo & 0.011 & - & - & - & - & - & 0.29 \\
\hline $\mathbf{P b}$ & - & - & - & - & 0.05 & - & 0.003 \\
\hline Sb & - & - & - & - & - & - & 0.08 \\
\hline Sn & - & - & - & - & - & - & 0.06 \\
\hline Th & - & - & - & - & - & - & 0.004 \\
\hline Tl & - & 0.10 & - & - & - & - & 0.09 \\
\hline $\mathbf{V}$ & 0.002 & - & - & - & 0.01 & 0.12 & 0.08 \\
\hline $\mathbf{U}$ & 0.0004 & - & - & - & - & - & 0.002 \\
\hline
\end{tabular}

Table 3. Trueness and Precision for SF-ICP-MS Analysis of CASS-6 $\left(\mu g \mathrm{~L}^{-1} \pm \sigma ; n=3\right)$

\begin{tabular}{|c|c|c|c|c|c|c|c|c|}
\hline \multirow[b]{2}{*}{ Metal } & \multirow[b]{2}{*}{$\begin{array}{l}\text { Certified } \\
\text { value }\end{array}$} & \multirow[b]{2}{*}{$\begin{array}{l}\text { Confidence } \\
\text { interval }\end{array}$} & \multicolumn{2}{|c|}{ September 8th } & \multicolumn{2}{|c|}{ September 16th } & \multicolumn{2}{|c|}{ October 10th } \\
\hline & & & Measured value & $\begin{array}{l}\text { Recovery } \\
(\%)\end{array}$ & Measured value & $\begin{array}{l}\text { Recovery } \\
(\%)\end{array}$ & Measured value & $\begin{array}{l}\text { Recovery } \\
(\%)\end{array}$ \\
\hline $\mathbf{A s}^{\mathbf{a}}$ & 1.04 & $0.94-1.14$ & $1.08 \pm 0.11$ & 104 & $1.09 \pm 0.07$ & 105 & $0.97 \pm 0.08$ & 93 \\
\hline Cd & 0.022 & $0.020-0.024$ & $0.024 \pm 0.007$ & 109 & $0.020 \pm 0.004$ & 91 & $0.024 \pm 0.005$ & 109 \\
\hline Mn & 2.22 & $2.10-2.34$ & $2.1 \pm 0.1$ & 95 & $2.03 \pm 0.05$ & 91 & $2.31 \pm 0.05$ & 104 \\
\hline Mo & 9.15 & $8.63-9.67$ & $8.8 \pm 0.4$ & 96 & $9.67 \pm 0.03$ & 106 & $8.62 \pm 0.04$ & 99 \\
\hline $\mathbf{P b}$ & 0.011 & $0.007-0.015$ & $0.012 \pm 0.004$ & 109 & $0.012 \pm 0.004$ & 105 & $0.012 \pm 0.003$ & 109 \\
\hline$V^{a}$ & 0.50 & $0.38-0.62$ & $0.47 \pm 0.01$ & 94 & $0.48 \pm 0.02$ & 96 & $0.48 \pm 0.03$ & 96 \\
\hline $\mathbf{U}$ & 2.92 & $2.5-3.3$ & $2.8 \pm 0.1$ & 96 & $2.84 \pm 0.05$ & 97 & $2.86 \pm 0.04$ & 98 \\
\hline
\end{tabular}

${ }^{a}$ Reference values.

the matrix effect on instrumental sensitivity, which shows itself in the functioning of ion optics. Therefore, prior to injection, the seawater samples need to be diluted. From previous studies, typical dilution factors used for the direct analysis of seawater do not exceed $10 .{ }^{9-12}$ We found that a 100 -fold dilution is superior for system performance pertaining the accuracy of the obtained results and eliminates signal suppression due to the high sea-matrix salinity (for common metal constituents, i.e., $\mathrm{K}, \mathrm{Ca}$, and $\mathrm{Mg}$, a higher dilution factor of 1000 was found more practical). This ensures sufficiently low limits of detection (LODs) to quantify a variety of toxic metals found at typical seawater concentrations not influenced by high anthropogenic input, which in many cases compared well with the sensitivity thresholds obtained by other investigators (where available for direct analysis, see Table 2). It should be mentioned that the fairly lower LODs reported by Field et al. ${ }^{10}$ were due to using a complicated nebulization setup, a shielded torch, and hot plasma high-resolution ICP-MS.

Method validation. Since the only sample treatment used was dilution, and the dilution factors were multi-fold, it was deemed obligatory to run blank analyses for evaluating contamination or spectral interference effects (with complex matrices, not all interferences could be separated, even when using the SF technique ${ }^{4}$ ). The precision of the method was determined by analyzing the CASS-6 CRM on three different days (the data summarized in Table 3). It can be seen that trueness, calculated from the deviations of the certified values as a percentage recovery,
Table 4. Limits of quantification $\left(\mu \mathrm{g} \mathrm{L}^{-1}\right)$

\begin{tabular}{llll}
\hline Metal & LOQ & Metal & LOQ \\
\hline As & 0.00051 & Sn & 0.22 \\
Bi & 0.35 & Th & 0.018 \\
Mn & 0.42 & $\mathrm{Tl}$ & 0.31 \\
Mo & 0.86 & $\mathrm{~V}$ & 0.14 \\
Pb & 0.009 & $\mathrm{U}$ & 0.0066 \\
Sb & 0.16 & & \\
\hline
\end{tabular}

varies from 94 to $109 \%$ and the results are within-day repeatable in the range from 3 to $5 \%$ (with an exception for the least abundant $\mathrm{Cd}$ and $\mathrm{Pb}$ ). The data of between-day measurements also accord fairly well since the calculated intermediate precision falls within the range of $3.8-9.1 \%$. The limits of quantification of the assay, defined as $10 \mathrm{\sigma} /$ slope of the calibration curve at a standard 100fold dilution, are presented in Table 4.

It is noteworthy to mention that the data for other metals that are less critical pollutants, including rare-earth elements, are not presented here and will be discussed elsewhere. Therefore, only some of the metals (as listed in Table 2) are included for systematic measurements as below. Of these, uranium and thorium are rather scarce but show a marked toxicity because of their radioactive properties.

Application to marine samples. There are various sources of material that deposit on the seafloor to form marine sediments, and most of these may cause sediment contamination from toxic 

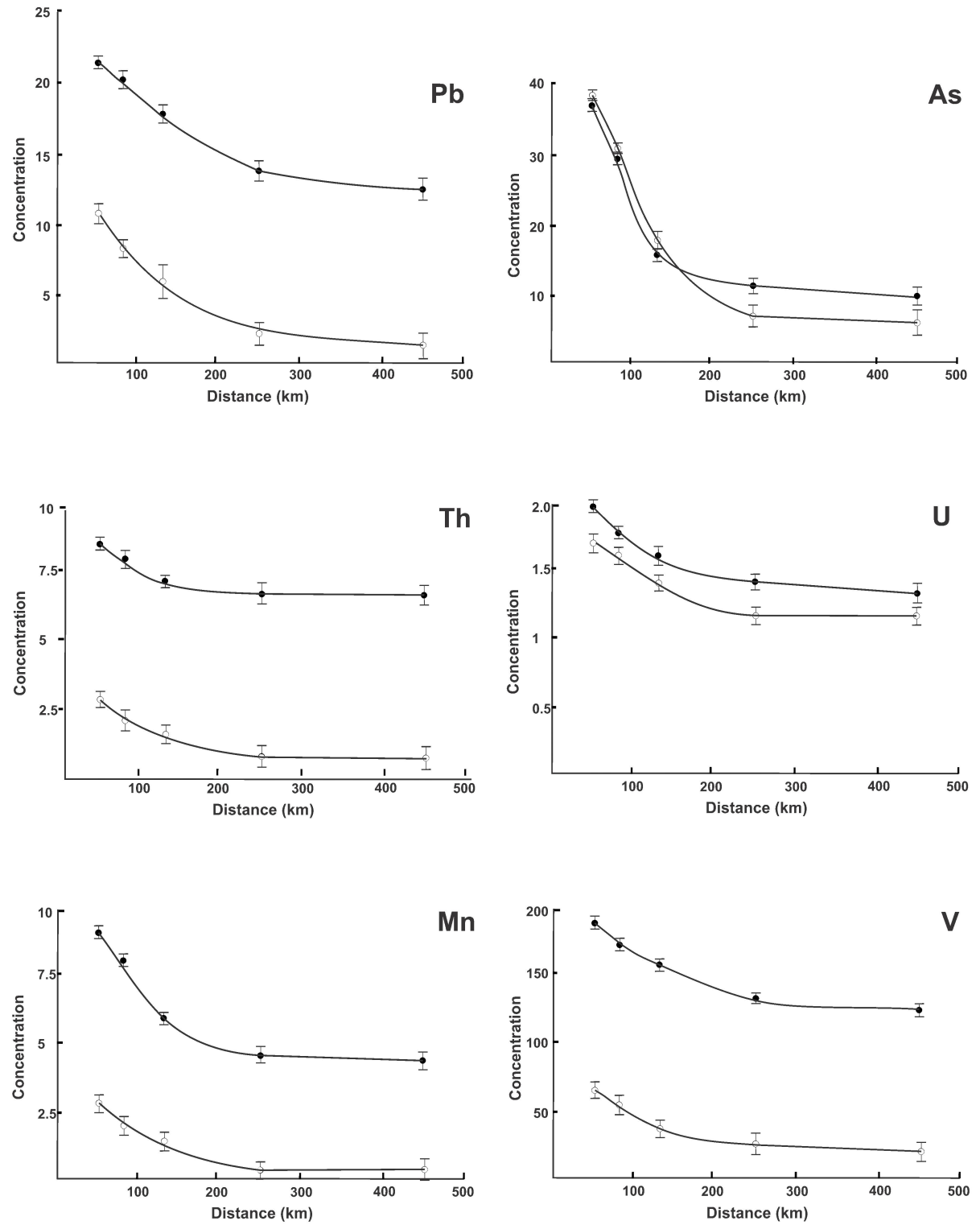

Fig. 2 Metal concentrations in seawater (open circles; $\mu \mathrm{g} \mathrm{L}^{-1}$ ) and surface sediment (black circles; $\mu \mathrm{g} \mathrm{g}^{-1}$ ) at different distance from the coast. For manganese, the concentrations are given in $\mathrm{mg} \mathrm{L}^{-1}$ and $\mathrm{mg} \mathrm{g}^{-1}$, respectively.

metals. Our earlier research ${ }^{15,23}$ suggests that it is insoluble material, primarily rock and soil particles, transported from land areas to the sea by rivers (mostly by the Ob River in this case), that has the greatest ecological impact. For the reason of proving this hypothesis, the simultaneous analysis of bottom seawater and upper sediment layer samples, collected as described in the Sampling subsection, was undertaken in this study.

The typical dependence of the heavy metal concentration of As, $\mathrm{Mn}, \mathrm{Pb}, \mathrm{Th}$, and $\mathrm{U}$ is based on the distance from the coast and is shown in Fig. 2. For both types of sample material, they have a similar character with first a steady decrease and then a gradual flattening of the metal content based on the increase in the distance. The most plausible explanation of such concentration profiles is due to the mass transfer being marked from the estuary to about $250 \mathrm{~km}$ from the coastline and turning out to be negligible beyond this distance. As a result, the contribution of the contaminated material exported by the $\mathrm{Ob}$ River influx fades and far from the estuary, the toxic metal concentrations become fairly constant, corresponding to natural seawater levels.

To prove the latter occurrence, the seawater constituents of noncontaminant nature were quantified in the same seawater samples using SF-ICP-MS. Here it is necessary to mention that for offshore aquatic areas, seawater has a rather conservative composition which is directly connected with the components included in Table 5. From the comparison of the concentrations of minor conservative metals at different distances from the shore and their global open 
Table 5. Minor Conservative Seawater Metals Quantified at Different Distance from the Coast and Their Typical Offshore Concentrations (mg $\left.\mathrm{L}^{-1}\right)$

\begin{tabular}{|c|c|c|c|c|c|c|}
\hline \multirow[t]{2}{*}{ Metal } & \multicolumn{5}{|c|}{ Distance (km) } & \multirow{2}{*}{$\begin{array}{c}\text { Concentration in } \\
\text { ocean water }\end{array}$} \\
\hline & 50 & 80 & 130 & 250 & 450 & \\
\hline $\mathbf{K}$ & $82 \pm 3$ & $139 \pm 6$ & $320 \pm 12$ & $385 \pm 10$ & $390 \pm 13$ & 391 \\
\hline $\mathbf{L i}$ & $0.03 \pm 0.001$ & $0.04 \pm 0.001$ & $0.10 \pm 0.003$ & $0.14 \pm 0.005$ & $0.15 \pm 0.005$ & 0.14 \\
\hline $\mathbf{R b}$ & $0.04 \pm 0.002$ & $0.06 \pm 0.002$ & $0.11 \pm 0.003$ & $0.17 \pm 0.002$ & $0.17 \pm 0.003$ & 0.17 \\
\hline $\mathrm{Sr}$ & $1.5 \pm 0.1$ & $2.4 \pm 0.1$ & $5.6 \pm 0.3$ & $7.8 \pm 0.2$ & $7.9 \pm 0.2$ & 7.9 \\
\hline
\end{tabular}

${ }^{\mathrm{a}}$ Ref. 22.

ocean levels (in ref. 22), given in the table, it is evident that while initially affected by the influx of the river into the sea, the concentration of $\mathrm{K}, \mathrm{Sr}, \mathrm{Li}$, and $\mathrm{Rb}$ turns out to be invariable after $250 \mathrm{~km}$ from the estuary due to a faded dilution effect by freshwater. It is worth noting that for some target analytes, e.g., arsenic and cadmium, the concentrations measured after this distance are also typical for offshore areas that are far from natural or anthropogenic influences. ${ }^{24}$ This fact can be considered an additional demonstration of the validity of the proposed method.

\section{CONCLUSIONS}

While seawater analysis belongs to the most often-used active applications areas of ICP-MS, ${ }^{25-27}$ the direct determination of trace metals remains a key sticking point. In the present study, we present a simple strategy for the direct analysis of offshore seawater, employing higher sample dilutions than accustomed in the reports of previous research. The results from the simultaneous determination of $\mathrm{As}, \mathrm{Cd}, \mathrm{Mn}, \mathrm{Mo}, \mathrm{Pb}, \mathrm{U}$ and $\mathrm{V}$ in the CRM and the longitudinal profiling of the Arctic Ocean water are in good agreement with certified and global open ocean values, respectively. The performance characteristics, obtained due to high sensitivity and resolution as well as the robustness of the SFICP-MS method, suggest its utility for a broader range of analytes. Furthermore, unlike previous methods relying on the concentration and separation of trace metals from the seawater matrix, our approach allows the sample throughput to be greatly increased. Another important aspect of the method is that in combination with marine sediment analysis, it lends itself to gaining geochemically important results, such as assessing the extent of sediment contamination by toxic metals or the effect of river influx on marine ecosystems.

\section{AUTHOR INFORMATION}

\section{Corresponding Author}

*Olga Kuznetsova

Email address: olga-kuznetsova0@mail.ru

\section{Notes}

The authors declare no competing financial interest.

\section{ACKNOWLEDGMENTS}

We would like to thank Dr. V. K. Karandashev for technical support and providing valuable comments on this manuscript and N. V. Dushenko for his assistance with sample collection.

\section{REFERENCES}

1. W. Bu, J. Zheng, Q. Guo, T. Aono, K. Tagami, S. Uchida, H. Tazoe, and M. Yamada, J. Chromatogr. A, 2014, 1337, 171-178. https://doi.org/10.1016/j.chroma.2014.02.066

2. I. Rapp, C. Schlosser, D. Rusiecka, M. Gledhill, and E. P. Achterberg, Anal. Chim. Acta, 2017, 976, 1-13. https://doi.org/10.1016/j.aca.2017.05.008

3. I. Wysocka and E.Vassileva, Spectrochim. Acta Part B: At Spectrosc., 2017, 128, 1-11. https://doi.org/10.1016/j.aca.2017.09.018

4. I. Rodushkin, C. Paulukat, S. Ponter, E. Engstroem, D. C. Baxter, D. Soerlin, N. Pallavicini, and K.Rodushkina, Sci. Tot. Environ., 2018, 622-623, 203-213. https://doi.org/10.1016/j.scitotenv.2017.11.288

5. K. Wuttig, A. T. Townsend, P. van der Merwe, M. Gault-Ringold, T. Holmes, C. Schallenberg, P. Latour, M. Tonnard, M. J. A. Rijkenberg, D. Lannuzel, and A. R. Bowie, Talanta, 2019, 197, 653-668. https://doi.org/10.1016/j.talanta.2019.01.047

6. K. Norisuye and Y. Sohrin, Anal. Chim. Acta., 2012, 727, 71-77. https://doi.org/10.1016/j.aca.2012.03.042

7. F. Queroue, A. Townsend, P. van der Merwe, D. Lannuzel, G. Sarthou, E. Bucciarelli, and A.Bowie, Anal. Methods, 2014, 6, 2837-2847. https://doi.org/10.1039/C3AY41312H

8. E. Vassileva, I. Wysocka, A. M. Orani, and C. Quetel, Spectrochim. Acta Part B: At Spectrosc., 2019, 153, 19-27. https://doi.org/10.1016/j.sab.2019.01.001

9. C. Turetta, G. Cozzi, C. Barbante, G. Capodaglio, and P. Cescon, Anal. Biochem. Chem, 2004, 380, 258-268. https://doi.org/10.1007/s00216-004-2676-0

10. M. P. Field, M. LaVigne, K. R. Murphy, G. M. Ruiz, and R. M. Sherrell, J. Anal. At. Spectrom. 2007, 22, 1145-1151. https://doi.org/10.1039/B617597J

11. J. Zheng, M. Yamada, T. Aono, and M. Kusakabe, J. Radioanal. Nucl. Chem., 2006, 270, 669-675. https://doi.org/10.1007/s10967-006-0446-5

12. P. Boening and B. Schnetger, Talanta, 2011, 85, 1695-1697. https://doi.org/10.1016/j.talanta.2011.06.031

13. C. Fahlgren, L. Gómez-Consarnau, J. Zábori, M. V. Lindh, R. Krejci, E. M. Mårtensson, D. Nilsson, and J. Pinhassi, Environ. Microbiol. Rep., 2015, 7, 460-470. https://doi.org/10.1111/1758-2229.12273

14. J. Zabori, R. Krejci, J. Strom, P. Vaattovaara, A. M. L. Ekman, M. E. Salter, E. M. Martensson, and E. D. Nilsson, Atmos. Chem. Phys., 2013, 13, 4783-4799. https://doi.org/10.5194/acp-13-4783-2013 
15. O. V. Kuznetsova, Y. V. Bychkova, and A. R. Timerbaev, Anal. Lett., 2020, 53, 563-573.

https://doi.org/10.1080/00032719.2019.1658200.

16. H. Papaefthymiou and G. Papatheodorou, J. Radioanal. Nucl. Chem., 2011, 289, 679-688. https://doi.org/10.1007/s10967-011-1143-6

17. O. V. Kuznetsova, Z. P. Burmii, T. V. Orlova, V. S. Sevastyanov, and A. R. Timerbaev, Talanta, 2019, 200, 468-471. https://doi.org/10.1016/j.talanta.2019.03.001

18. V. K. Karandashev, V. A. Khvostikov, S. Yu. Nosenko, and Zh. P. Burmiy, Inorg. Mater., 2017, 53, 1432-1441. https://doi.org/10.1134/S0020168517140084

19. M. P. Field, J. T. Cullen, and R. M. Sherrell, J. Anal. At. Spectrom., 1999, 14, 1425-1431. https://doi.org/10.1039/A901693G

20. H. Louie, M. Wu, P. Di, P. Snitch, and G. Chapple, J. Anal. At. Spectrom., 2002, 17, 587-591. https://doi.org/10.1039/b109121m
21. D. Rahmi, Y. Zhu, E. Fujimori, T. Hasegawa, T. Umemura, S. Konagaya, and H. Haraguchi, Anal. Sci., 2008, 24, 1189-1192. https://doi.org/10.2116/analsci.24.1189

22. M. Grotti and R. Frache, J. Anal. At. Spectrom., 2007, 22, 1481-1487. https://doi.org/10.1039/b711107j

23. O. V. Kuznetsova and A.R. Timerbaev, Anal. Lett., 2021, 54, 442-452. https://doi.org/10.1080/00032719.2020.1767123

24. K. Fukushi, T. Hirokawa, and A. R. Timerbaev, J. Chromatogr. A, 2019, 1606, 360240. https://doi.org/10.1016/j.chroma.2019.05.020

25. Y. Sohrin and K. W. Bruland, Trends Anal. Chem., 2011, 30, 1291-1307. https://doi.org/10.1016/j.trac.2011.03.006

26. J. Ma, D. Yuan, K. Lin, S. Feng, T. Zhou, and Q. Li, Trends Environ. Anal. Chem., 2016, 10, 1-10. https://doi.org/10.1016/j.teac.2016.02.003

27. I. R. B. Olivares, G. B. Souza, A. R. A. Nogueira, G. T. K. Toledo, and D. C. Marcki, Trends Anal. Chem., 2018, 100, 53-64. http://dx.doi.org/10.1016/j.teac.2016.02.003 